материального и духовного производства и т.д.); 5) демографической принадлежности билингва (возраст, пол, образование и т.д.).

$$
* * *
$$

1. Верещагин Е. М. Психологическая и методическая характеристика двуязычия (билингвизма) / Е. М. Верещагина. Москва: Изд-во МГУ, 1973. С. 22-23.

2. Лингвистический энциклопедический словарь / Гл. ред. В. Н. Ярцева. Москва.: Сов. энциклопедия, 1990. - 685с.: ил. ISBN 5-85270-031-2

3. Багироков Х. 3. Билингвизм: теоретические и прикладные аспекты (на материале адыгейского и русского языков): Монография / Х. З. Багироков. Майкоп: Изд-во АГУ, 2004. 316с.

4. Убайдулаев Р. У. К вопросу о фонетической интерференции / Р. У. Убайдулаев // Русский язык и литература в таджикской школе. 1971. №4. С. 3-12.

5. Блягоз 3. У. Адыгейско-русское двуязычие: автореф. дис. на соиск. учен. степ. д-ра филол. наук / 3. У. Блягоз. Киев. 1980. С. 52.

6. Шейнина Е. П. Работа над диалектными ошибками в речи учащихся / Е. П. Шейнина // Рус. яз. в школе. 1963, №4. С. 26-28.

7. Аутлев К. Д. Артикуляционная характеристика гласных адыгейского языка (рентгенологическое исследование) // К. Д. Аутлев. Майкоп, 1974. С. 229-238.

\title{
Заварзина Г.А. \\ Терминология рынка в сфере современного российского государственного управления
}

Воронежский государственный педагогический университет (Россия, Воронеж)

doi $10.18411 / g q-31-03-2021-56$

idsp sciencerussia-31-03-2021-56

\section{Аннотация}

В статье представлена типология экономических терминологических номинаций, активно функционирующих в сфере современного российского государственного управления. В терминологии рынка выделены и охарактеризованы два лексико-семантических разряда: наименования явлений и понятий, отражающие особенности нового государственного управления в экономике, а также наименования рыночных (экономических) явлений и понятий, характеризующих особенности системы нового государственного управления России. Отмеченное явление обусловлено активным использованием рыночных методов и принципов в построении модели нового управленческого аппарата в Российском государстве.

Ключевые слова: рыночные номинации, терминология, экономоцентричность, государственное управление, атрибутивные характеристики, предикативные характеристики.

\section{Abstract}

The article presents a typology of economic terminological categories that are actively functioning in the field of modern Russian public administration. In the terminology of the market is isolated and characterized two lexical-semantic category: names of phenomena and concepts, reflecting the characteristics of the new public management in the economy, as well as the names of the market (economic) phenomena, and concepts describing the features of the new public management in Russia. This phenomenon is due to the active use of market methods and principles in building a model of a new administrative apparatus in the Russian state.

Keywords: market nominations, economocentricity, public administration, attributive characteristics, predicative characteristics. 
В новейший период развития российского общества происходит активное использование методов и принципов рынка в построении модели нового государственного управления, что обусловливает использование лексических единиц экономического содержания для характеристики деятельности государства и государственных органов во всех без исключения сферах общественной жизни. Не случайно государственное управление в новейший период получило наименование «новый государственный менеджмент», что свидетельствует об активном пополнении данного лексического пласта номинациями экономической (менеджеральной) сферы. Отмеченное явление подтверждается материалами политологических исследований и средств массовой информации. Ср.: «...нацеленность на качественное предоставление услуг гражданам и гражданским ассоциациям - показатель демократического курса реформы, которая имеет т.н. «экономоцентричный» вектор движения» [1].

Следует отметить, что рыночные номинации, активно функционирующие в сфере современного российского государственного управления, могут быть представлены лексико-тематическими группами двух типов: 1) наименованиями явлений и понятий, отражающих особенности нового государственного управления в экономике; 2) наименованиями рыночных (экономических) явлений и понятий, характеризующих особенности системы нового государственного управления России [2]. Применение подобной классификации номинаций на две указанные группы обусловлено закрепившимся разделением в новом государственном управлении РФ властных (политических) и собственно экономических функций. Ср.: «Господство либеральных ценностей и выражающее его понятие экономический человек вызвало к жизни понятие «госуправление», то есть основу, противоположную единовластию и непосредственному делегированию властных и экономических полномочий» [3].

Среди наименований явлений и понятий, отражающих особенности нового государственного управления в экономике, выделяются:

1. Номинативы, отражающие особенности нового государственного управления в экономике: а) обозначения государственных мероприятий, направленных на закрепление относительной самостоятельности экономической сферы (ср.: снижение административных барьеров в бизнесе, уменьшение налоговой нагрузки, модернизация экономики, дерегулирование предпринимательской деятельности, централизация информации о проверках, сокращение бюджетных вливаний в экономику и др.); б) обозначения государственных документов, регулирующих развитие рыночной сферы (ср.: доктрина, способ сочииальной защчтыь, челевая программа; план Путина, инвестпроекты, реформа бюджетной системы; антикризисный пакет, согламение о разделе продукиии, постановления и др.); в) наименования субъектов рынка (ср.: маклер, бизнесмен, представители бизнеса, капитаны российской промылиленности, менеджер, белье (серыеl расстегнутые, голубые, синие) воротнички, бизнессообщества, продавеи, покупатель, клиент и др.); г) наименования платежных средств и процессов (ср.: денежные средства, акция, выплаты, ценная бумага, кредит, зарплата, потолок заработной платы, пенсии, субсидии, субвенции, трансферты;; социальный пакет, дивиденды, бонусы, сочииальные карты, инфраструктурные и «проектные» облигации и др.); д) обозначения новых элементов инфраструктуры рынка (ср.: конкурсы, аукционы (компьютерные), ярмарки, компании, биржа, корпорация, банк, акционерное общество, зона свободного предпринимательства, торговые площадки, электронные торги, бизнес-парки, бизнес-единиџь, предприятия реального сектора, сочиальная инфраструктура, экономические форумы и др.).

2. Атрибутивные характеристики понятий, отражающих особенности нового государственного управления в сфере экономики (ср.: прозрачные компании, сбалансированный бюджет, ответственная макроэкономическая политика, высококонцентрированный сегмент рынка, программно-целевой метод составления 
бюджета, долгосрочный инвестиционный ресурс, либеральная экономическая политика, теневая экономика и др.)

3. Предикативные характеристики явлений и понятий, отражающих особенности нового государственного управления в сфере экономики (ср.: отпустить цены, создать вертикаль регулирования рынка, подготовить бюджет, распределять финансовые потоки, построить модель бюджетной сети, собирать налоги, перестать действовать жестокими методами, убрать барьерь для бизнеса, контролировать надзор бизнеса, усовершенствовать инфраструктуру финансового рынка, обеспечить стабильность бюджетной системы и др.) [4].

Среди наименований рыночных (экономических) явлений и понятий, характеризующих особенности системы нового государственного управления России, выделяются: 1) обозначения важнейших явлений в сфере государственного управления (ср.: экономизация власти, экономика электронного правительства, менеджеральный подход к госуправлению, государственный менеджмент, управленческий менеджмент, политический рынок, маркетинговая конщепџия госуправления, торговые операџии в политике, реинжсиниринг госуправления, менеджеризащия госаппарата, аудит деятельности госорганов, административный рынок, бюджетирование госуправления, аутсорсинг в органах госуправления и др.): «Высшая власть в современных условиях выступает как верховный арбитр теневой ресурсной конкуренции»; "Суть нового этапа можно определить как переход от формирования концепции к экономике электронного правительства»; «Именно маркетинговая концепция государственного управления долюна обеспечить более эффективное и качественное выявление, формирование и удовлетворение потребностей потребителей» (из газет); 2) обозначения видов госуправления (ср.: рыночный тип государственного управления, предпринимательское государственное управление, менеджеральная модель госуправления и др.); 3) обозначения методов государственного управления (ср.: эффективность госуправления, продуктивность госуправления, производительность госуправления, рыночная оценка деятельности госструктур, финансовая оченка деятельности государственных органов, информационно-менеджеральный метод государственной политики, государственный маркетинг, маркетинговый подход $к$ госуправлению, ваучерный метод государственной политики, политическая рентабельность, политическая ликвидность, издержки деятельности госорганов и др.): «Продуктивность профессиональной управленческой деятельности государственных служаших федерального уровня управления является системно организованной, интегративной характеристикой»; “Очевидна необходимость обеспечения маркетингового подхода к государственному управлению как в целом, так и при проведении отдельных мероприятий» (из газет); 4) обозначения негативных явлений в сфере госуправления (ср.: риски, транзакциионые издержки, коммерциализации и др.): «Государство неэффективно: это значит, что транзакционные издержки госуправления растут быстрее, чем ВВП»; «Во-первых, произошла стремительная коммеричализация выборов, во-вторых, резко возросла роль административного ресурса, контролируемого региональнылми элитами» (из газет); 5) названия лиц, участвующих в осуществлении государственного управления (ср.: государственный менеджер, сетевой менеджер страны, сити-менеджер, менеджер государства, менеджер партии, брокер, маклер, акиионеры и др.) [5]: «Путин - это просто сетевой менеджер»; «Глава государства - менеджер своей страны»; «Президент - менеджер, депутаты - биржевые маклеры, а народ дешевый товар?»; “Большое значение имеет тот факт, что Медведев - менеджер, единственный, на наш взгляд, из многих потенциальных кандидатур занимал пость и на региональном, и на федеральном уровне, работал в Кремле» (из газет). 
Таким образом, особенности функционирования рыночной терминологии в сфере государственного управления современной России, с одной стороны, отражают процессы ослабления регулирующего воздействия государственного управления на систему современного рынка, a c другой стороны, подтверждают активное использование методов и принципов рынка в новой модели отечественного государственного управления.

$$
* * *
$$

1. Лазарев А. М. Концептуальные основы и практика современного административного реформирования (сравнительно-политологический анализ): дис. канд. политич. наук/ А.М. Лазарев. - М, 2009.

2. Заварзина Г.А. Русская лексика государственного управления: история формирования и современные процессы развития: дис. доктора...филол. наук. - Воронеж, 2015. - 381 с.

3. Егоров В.С. Государственная служба сегодня подменяет государственное управление//Независимая газета. - 02.11.2000. - С.2-4.

4. Zavarzina G.A. Actual problems of terminological system development of new state administration / G.A. Zavarzina, T.N. Dankova// The International Scientific and Practical Conference "Current Issues of Linguistics and Didactics: The Interdisciplinary Approach in Humanities and Social Sciences”. - Volume 69. -2019.

5. Заварзина Г.А. Новые системные связи в структуре ЛСП «Государственное управление» // Современные проблемы лингвистики и методики преподавания русского языка в вузе и школе. Выпуск 27. - Воронеж: ИПЦ «Научная книга», 2017. - С. 3-5.

\section{Коляда Н.А. \\ Значимость развития навыков межкультурного общения при обучении иностранным языкам}

Южный Федеральный университет (Россия, Ростов-на-Дону)

doi 10.18411/gq-31-03-2021-57

idsp sciencerussia-31-03-2021-57

\section{Аннотация}

Рассматривается преподавание иностранного языка как средства повседневного общения с носителями другой культуры. Особое внимание уделяется межкультурному обучению, способствующему достижению межкультурной коммуникации. Предлагаются возможности для развития способностей и навыков межкультурного общения с привлечением материала лингвострановедческого содержания, приводятся примеры упражнений для развития и закрепления навыков межкультурного общения, направленные на умение интерпретировать существующие различные модели восприятия мира, соотносить иные культурные обычаи и нравы со своими поведенческими нормами.

Ключевые слова: иноязычная коммуникация, концепция коммуникативного обучения, лингвострановедческий материал, культура и язык.

\section{Abstract}

The article considers teaching a foreign language as a means of everyday communication with native speakers of another culture. Special attention is paid to crosscultural learning, which contributes to the achievement of cross-cultural communication. The article offers opportunities for developing the abilities and skills of cross-cultural communication with the involvement of the material of linguistic and cultural content, provides examples of exercises for the development and consolidation of cross-cultural communication skills, aimed at the ability to interpret the existing various models of perception of the world, to relate other cultural customs and mores with their behavioral norms.

Keywords: foreign language communication, the concept of communicative learning, linguistic and foreign studies material, culture and language. 